\title{
Building climate change resilience in California through UC Cooperative Extension
}

\author{
A survey of UC ANR academics found opportunities for expanding the role of climate change \\ in extension work.
}
Theodore Grantham, Assistant Cooperative Extension Specialist, Department of Environmental Science,
Policy, and Management, University of California, Berkeley

Faith Kearns, Academic Coordinator, California Institute for Water Resources

Susie Kocher, Forestry and Natural Resources Advisor, Central Sierra Cooperative Extension

Leslie Roche, Assistant Cooperative Extension Specialist, Department of Plant Sciences, University of California, Davis

Tapan Pathak, Assistant Cooperative Extension Specialist, Sierra Nevada Research Institute, University of California, Merced

Snowmelt fills the South Yuba River near Emigrant Gap in March 2016. Climate change is expected to reduce the Sierra snowpack, resulting in major shifts in the timing and magnitude of flows in rivers fed by snowmelt.

$$
\longrightarrow
$$

limate change is a global challenge. Yet, the impacts are local and already being felt in Califor- including the recent swing from a 5-year drought to one of the wettest winters on record - are indicative of a warmer, more variable climate future. The changing climate has already begun to stress our social, economic and ecological systems. It is threatening crops, increasing catastrophic wildfires, harming fish and wildlife, limiting water supplies while also increasing flood risk, and ultimately impacting the health and quality of life for Californians.

The University of California's Division of Agriculture and Natural Resources (UC ANR) has worked with Californians for more than 100 years through its statewide network - which includes UC Cooperative Extension and the Agricultural Experiment Station campuses - to solve problems in agriculture, natural resources and food systems.
Climate change compounds these problems, making it more difficult for UC ANR to achieve its vision for "a thriving California in 2025 where healthy people and communities, healthy food systems, and healthy environments are strengthened through partnerships between UC and the people of the state."

UC ANR academics and staff are mobilizing to address the threat of climate change. In November 2013, UC President Janet Napolitano announced the Carbon Neutrality Initiative (CNI). The initiative committed UC to emitting net zero greenhouse gases from its buildings and vehicle fleet by 2025 , the first commitment of its kind by any major university. Within UC ANR, the CNI provided small financial incentives for academics to develop climate change-related projects across many program areas, including agriculture, natural resources, nutrition and youth development.

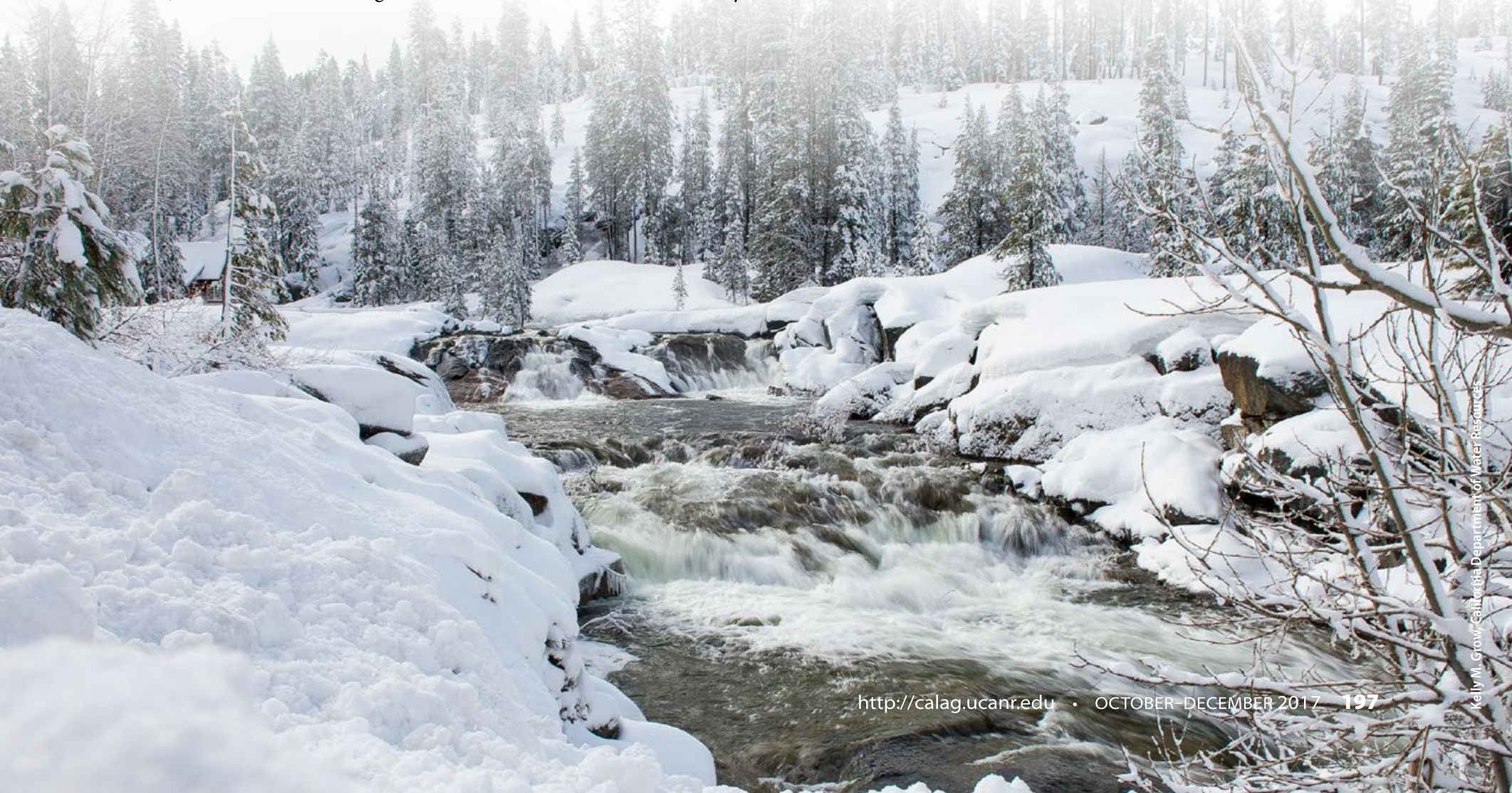


Fig. 1. Results from the UC ANR climate science, outreach, and needs survey.
UC ANR leadership also supported the establishment of a climate change program team in 2015, with the primary goal of building capacity within UC Cooperative Extension to better serve the public in addressing climate change impacts and adaptation challenges. As members of the program team, we decided an important first step to support this goal was to assess the scope of current climate science research and extension within UC ANR. We designed and distributed an online survey in early 2017, reaching out to approximately 1,000 UC ANR faculty, specialists, advisors and staff to evaluate interests and experiences in incorporating climate change science into research and extension programs. We received feedback from 144 respondents (fig. 1).

We found that there was overwhelming agreement on the importance of addressing climate change (fig. 1). Nearly all respondents (88\%) believe it is important to incorporate information about climate change impacts, adaptation approaches, and mitigation strategies into extension programs. At the same time, fewer than half of the respondents (43\%) currently incorporate climate change in their extension programming in some way. Because responses were voluntary and probably overrepresented those interested in climate change, the actual percentage of ANR

\section{UC Agriculture and Natural Resources Climate science, outreach, and needs survey}

In 2017, the authors surveyed UC ANR scientists and outreach professionals. The 144 responses highlight the broad range of efforts by UC Cooperative Extension and the Agricultural Experiment Station in building climate change resilience across California, as well as opportunities to further grow capacity in these areas.

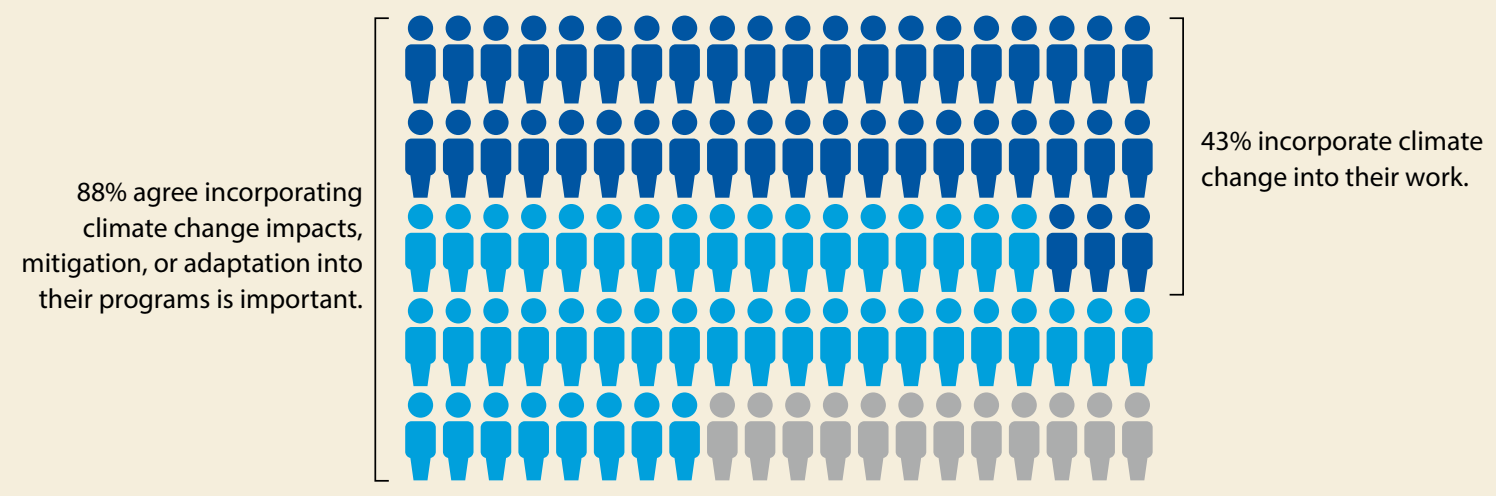

\section{Respondents}

County advisors

46

Community education specialists

38

Cooperative Extension specialists

23

Campus faculty

(Agricultural Experiment Station)

22

Academic coordinators and support personnel

\section{Area of expertise}

(324 unique responses; respondents could choose more than one area)

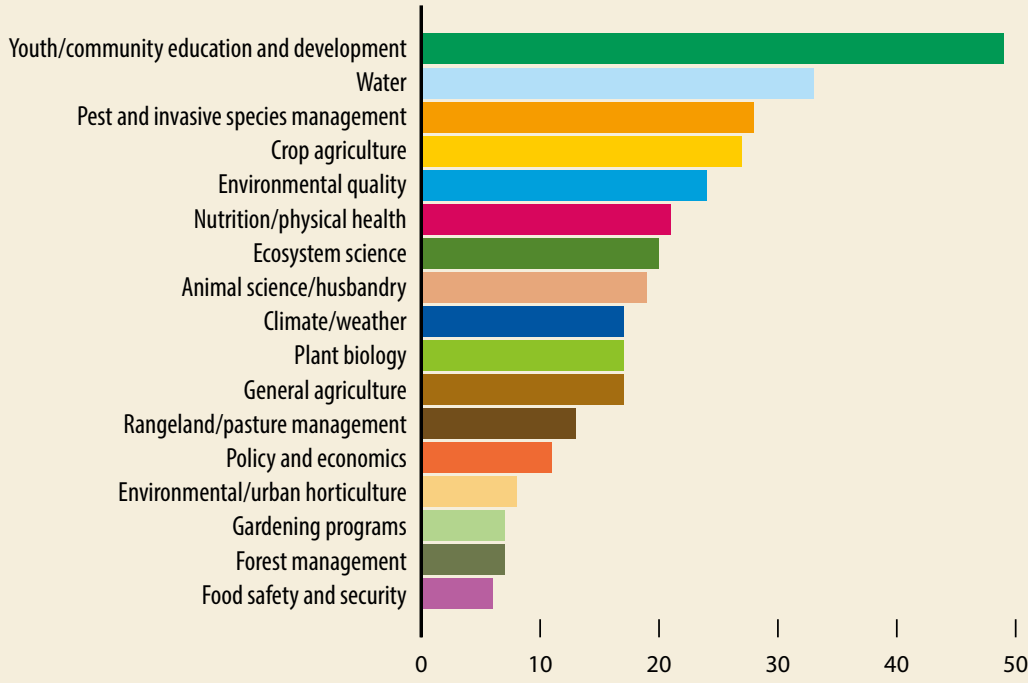

Primary clientele

Agriculture

$47 \%$

Natural resources

$22 \%$

Youth development

$17 \%$

Family and consumer science 
academics and staff directly engaging with climate change is likely lower.

Many respondents had a low level of confidence in their current ability to incorporate climate change in their extension programming. Perceived barriers included lack of access to climate information relevant to their extension programs and clientele, limited familiarity with climate science fundamentals, and fear of alienating clientele by talking about a contentious topic.

In addition, $25 \%$ of the respondents who currently incorporate climate change in their programming felt that they did not have adequate support from UC ANR to work on climate change issues. Respondents expressed interest in professional development opportunities, including education on technical tools and information resources, as well as training in climate science communication.

In summary, the survey revealed that UC ANR personnel recognize the importance of addressing climate change and that additional training and institutional support are critical for building capacity to incorporate climate change within extension programs. In response, the climate change program team is working to develop a series of workshops to address these barriers and to identify the tools, resources and information

\section{Concerns expressed by respondents who currently incorporate climate change into their extension programming}

1. No concerns

$35 \%$

2. Unsure about presenting complex climate data accurately $32 \%$

3. Don't feel they have adequate support from UC ANR to work on issue

$\mathbf{2 5 \%}$

4. Concerned about the reaction of clientele to climate change information

$22 \%$

\section{Topics covered currently by respondents} who are incorporating climate change into their extension programming

(101 unique responses; respondents could select more than one topic)

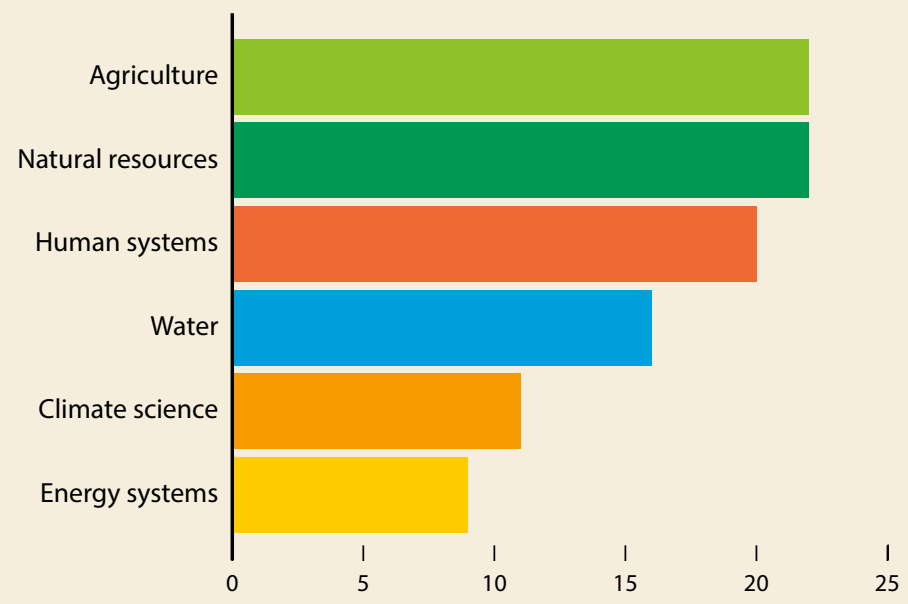

\section{Concerns expressed by respondents who do not currently incorporate climate change into their extension programming}

1. No access to curriculum specific to field $51 \%$

2. Unsure about presenting complex climate data accurately $32 \%$

3. Don't have good source of climate change information to share

$30 \%$

4. Concerned about the reaction of clientele to climate change information

$24 \%$

\section{Strategies used currently by respondents who are incorporating climate change into their extension programming}

(133 unique responses; respondents could select more than one strategy)

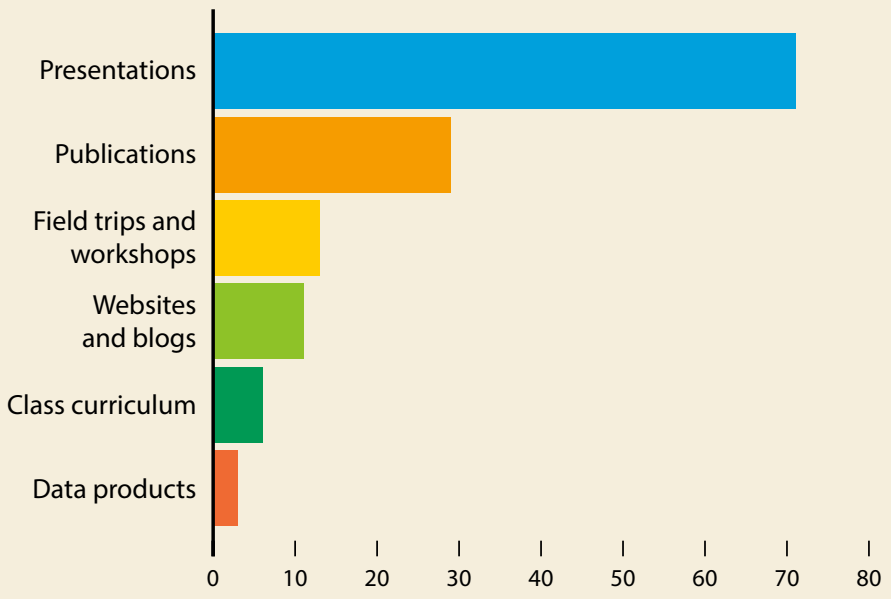


